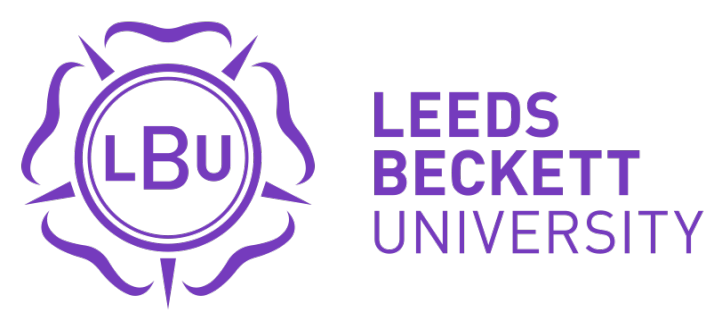

Citation:

Robinson, D and Spracklen, K (2019) Music, Beer and Performativity in New Local Leisure Spaces: Case Study of a Yorkshire Dales Market Town. International Journal of the Sociology of Leisure. ISSN 2520-8683 DOI: https://doi.org/10.1007/s41978-018-00029-5

Link to Leeds Beckett Repository record:

https://eprints.leedsbeckett.ac.uk/id/eprint/5536/

Document Version:

Article (Accepted Version)

The aim of the Leeds Beckett Repository is to provide open access to our research, as required by funder policies and permitted by publishers and copyright law.

The Leeds Beckett repository holds a wide range of publications, each of which has been checked for copyright and the relevant embargo period has been applied by the Research Services team.

We operate on a standard take-down policy. If you are the author or publisher of an output and you would like it removed from the repository, please contact us and we will investigate on a case-by-case basis.

Each thesis in the repository has been cleared where necessary by the author for third party copyright. If you would like a thesis to be removed from the repository or believe there is an issue with copyright, please contact us on openaccess@leedsbeckett.ac.uk and we will investigate on a case-by-case basis. 


\title{
Music, Beer and Performativity in New Local Leisure Spaces: Case Study of a Yorkshire Dales Market Town
}

\author{
Robinson, D.; Spracklen, K.
}

\begin{abstract}
Pubs and popular music share long-standing connections, both through commodified entertainment practices and ones which cultivate a sense of belonging. In this article we consider how new spaces for drink and music related leisure form sites of community, distinction and resistance in a Yorkshire Dales market town. Pubs in urban areas have long contributed to the vitality of more diffuse music scenes, but instances of pub-based scenes in rural areas have been rare and disconnected. However, the conjunction of reduced demand for retail space and an emergent do-it-yourself culture has brought about the transformation of redundant retail outlets as independently-run leisure spaces in both urban and rural locales, including a growing number of micropubs. Foregrounding the role of individual agency and the significance of locally-negotiated meanings, we examine how Habermasian communicative leisure is performed at recently-opened micropubs which stage live music. Through observational analysis and semi-structured interviews we examine how these performative spaces foster a sense of belonging and how this is enhanced through activities including music quizzes, trips to music festivals and amateur music-making. We consider how locally negotiated trading and exchange practices constitute resistance to corporate capitalism and the extent to which this community's preferences for real-ale and less-mainstream musical styles also serve as markers of distinction in a Bourdieusian sense.
\end{abstract}

Keywords: Community; Leisure; Authenticity; Music; Real-ale; Micropubs.

\section{Introduction ${ }^{1}$}

Leisure spaces are sites of a struggle over meaning and belonging. In the context of the post-industrial city, what may be regarded as either the reclamation or colonisation of previously rundown districts by artists and entrepreneurs constitutes a major area of interest amongst urban studies scholars (Florida, 2002, 2005; Heying, 2010; Lloyd, 2010; Long, 2010; Zukin, 2010; Zukin et al, 2009). Streetscapes of 'creative' urban enclaves are typically characterised by artisan shops, arts projects and alternative leisure spaces: music cafes, 'Slow Food' restaurants, craft beer bars and gallery spaces - elements of 'street level culture' as 'authentic' space, and symbols of resistance to the evermore homogenous features of the corporately-dominated cityscapes beyond. The geographer's term 'sense of place' is sometimes employed in this specifically postindustrial context (e.g. Long, 2010; Zukin, 2011) to describe the felt authenticity experienced within such alternatively-ordered urban locales. In exhibiting similar features of alternativity, city districts from Wicker Park, Chicago to Shoreditch, London

\footnotetext{
${ }^{1}$ Our initial findings were presented to the Leisure Studies Association conference in July 2017, and generated some useful feedback and interesting discussion around issues of gender which we aim to address in more detail in this paper.
} 
can evoke a similarly felt 'sense of place' for urbanites who identify as alternative and anti-corporate.

The term 'sense of place' inhabits the same subjective sociological realm as Raymond Williams' (1977) concept of 'structures of feeling', describing the qualities of social experience that give the sense of a generation or period. So too with Pierre Bourdieu's (1984) connected concepts of 'habitus' and 'cultural capital': the former referring to individuals tastes as being historically conditioned through class position, and the latter describing the symbolic status that individuals attain through demonstrating cultural competence. The quirky cafes and bars of the post-industrial city thus constitute stages on which young 'urbanites' assert and project cultural capital, demonstrating cultural competences through a set of aesthetic and ethical choices which set them apart from mainstream tastes and values. The same performativity of 'sense of place' is found in much sociology of leisure research, whether it is the imaginary community at the heart of sports fandom (Spracklen, 2016; Spracklen et al, 2010), or various alternative music scenes (Spracklen and Spracklen, 2014; Spracklen, 2017)

But whilst the urban hipster's claims on authentic place and space are well documented, as Sharon Zukin (2011) argues, gentrification and local entrepreneurialism are also evident in the construction of authentic sense of place in at least some rural areas of both Britain and North America. Amongst the emergent practices evident in new local leisure spaces is that of combining alcohol and music related leisure. As well as hipster bars with American-style craft beer ${ }^{2}$, and cafes which evoke the urban folk revival, the 'micropub' has introduced another category of leisure space in England and Wales which lends to acoustic musical performance and is suited to both urban and rural locales. The vision of former off-licensee Martyn Hillier, the concept of the micropub is made possible by the relaxation of licensing laws and the plentiful availability of small, low rent retail premises (see Hawkes, 2011). Typically a single room space, the micropub features independently brewed real ales amongst a limited drinks range (excluding draft lager) and eschews all forms of electronic entertainment in order to encourage conversation. Moreover, the concept complements a growing movement spearheaded by the Campaign for Real Ale (CAMRA) to promote the role of traditional pubs in UK culture as "centres of community life" (CAMRA, 2017).

In the context of reclaiming or recreating 'authentic space', the micropub connotes the idea of the 'ale house', a much mythologized place in English folklore, and in more rural settings may suggest a similarly imagined Englishness to that drawn upon by the English folk morris dance scene (see Spracklen and Henderson, 2013). As potential sites of resistance to global capitalism, micropubs might thus be seen as representations of a tradition to be defended, whilst their contemporary relevance can be explored both in terms of a search for community as embodied in the turn to 'localism' (Thurnell-Read,

\footnotetext{
${ }^{2}$ Craft beer has no legal definition. It is a marketing term that can be used and abused by big corporations as well as one-person breweries. It has come to mean beer made in a range of styles by brewers who copy the first craft breweries in the Unites States. Craft beer is dispensed in kegs and its secondary fermentation can often be stopped in the same way it is stopped in keg lager, and carbon dioxide is often added to make it fizzy. Real-ale is defined as beer that continues its secondary fermentation in the cask, and is dispensed through a hand-pump: this is the traditional British style of beer defended by the Campaign for Real Ale when it was first set-up in the 1970s.
} 
2011), and also in the quest for more democratic producer-consumer relations as observed in the performative role of real ale drinkers who exercise individual agency in their leisure choices (Spracklen et al, 2013). In this paper, we examine how the notion of a struggle between (individual/collective) 'communicative action' and the (structural) forces of 'instrumental reason', as theorised by Jurgen Habermas' (1984, 1987), plays out in the performative practices of a micropub scene in a Yorkshire Dales market town. Habermas' idea of the communicative rationality of the human lifeworld being swamped by the instrumentality of global capitalism is used here because it forms the basis of Spracklen's (2009) theory of communicative leisure and instrumental leisure. Communicative leisure is freely chosen, and used to define meaning and purpose, identity and belonging; instrumental leisure, on the other hand, is the leisure that is sold to humans in commodified forms, and which is used to limit agency and ensure the interests of hegemonic elites are maintained.

In this context, then, we examine how and to what extent these new leisure spaces, individually and collectively, form sites of Habermasian communicative action and to what extent they are constrained by forces of instrumental consumption (Habermas, 1984, 1987). We consider how preferences for real ale and non-mainstream music form markers of distinction in a Bourdieusian sense, and the ways in which these preferences as experienced in a localised context can foster a sense of belonging within both a 'knowing' and a 'knowable community', which excludes others of 'inferior' or more mainstream taste. We examine how ideas of 'local' correspond with values of independent entrepreneurship and 'DIY' culture as evident in the creative and exchange practices carried out in these leisure spaces; we consider how these values and practices constitute a reclamation of 'authentic space', and the extent to which they contribute to a distinctive 'sense of place' for an emergent cohort of alternativelypositioned rural/small town-dwellers. And whilst this emergent community may attach value to elements of a 'residual culture' (Williams, 1977), a further and significant consideration in our research is the temporary and fluid nature of some of the practices and relationships observed.

\section{Research Context and Methodology}

Skipton (population 15,000) is a small market town in North Yorkshire located in between the Yorkshire Dales National Park to the North and the former mill towns of West Yorkshire and East Lancashire to the South. The town's main economic activity centres around financial services, light industry, agriculture and tourism. Its visitor attractions include a medieval castle, a street market and the Leeds-Liverpool Canal. Being situated at the intersection of two transpennine trunk roads and having direct rail services to Leeds and Bradford, Skipton has convenient transport connections for tourists and commuters alike. So too, quality of life indicators help to draw affluent commuters and retirees to the town, whilst high-performing schools make Skipton a place of choice for parents with school-age children. As well as the more affluent incomers, the town remains home to a long-established working-class community. Many of them are descendents of textile workers and now supply labour to locally-based engineering, manufacturing and service sector employers, although a shortage of affordable housing makes it increasingly difficult for younger working-class adults to remain in the town. 
This case study focuses on a small area of Skipton recently dubbed the 'Canal Quarter', and specifically on three micropubs which opened in close proximity to each other over a two year period between spring 2014 and spring 2016. These leisure spaces exhibit the following features in common: they are each run by small-scale entrepreneurs; to a greater or lesser extent they each conform to Hillier's concept of a micropub; as well as serving real ale they each host live music sessions on a regular basis; and whilst each attracts tourist business, a large proportion of their trade is local and regular. They also differ in character from each other in ways which we describe in the following section.

Our research is concerned with these spaces as sources of meaning for the idea of 'local'. The researchers live in the town and have observed the emergence of a micropub scene in which local people have come to perform leisure through the shared experience of alcohol and music; in particular, real ale and live music. The field work for this study was carried out over a six month period during the spring and summer of 2017, and involved a combination of interviews and participant observation. We recorded semi-structured interviews with 12 key respondents: micropub owners, musicians, real ale drinkers and music fans. ${ }^{3}$ The four owners and two musicians interviewed were all males. Of the other six interviewees, two were female music fans, one of whom was also a real ale drinker; and the four males were each, to differing extents, both real ale drinkers and music fans. With the exception of one of the females, all the other respondents were white. This small sample included maximum variation of regular scene participants as evidenced by initial participant observation. The sample spanned the predominant mid-thirties to mid-sixties age range and the observed range of socio-economic groups, as well as approximating to the male-to-female ratio of scene regulars. The single non-white participant was included in the context of an overwhelmingly white-inhabited scene. Interviewees were not specifically questioned about their class identities, but their occupational histories covered a range of job categories including care worker, valve technician, health service administrator and solicitor.

The interviews were prearranged, and took place at the micropubs during quiet times; each taking between 45 minutes and an hour to complete. All the interviews commenced with biographical questions, which included inviting participants to discuss their own relationships with music and alcohol related leisure. Questions to micropub owners and musicians then focused on their individual experiences and motivations: why, for example, they chose to locate in Skipton's Canal Quarter; what groups of customers/audiences they aim to attract; and how their involvement in the scene reflects their own tastes and values. Questions to micropub customers focused on their tastes in music and alcohol; what attracts them to the Canal Quarter scene; and what is special or distinctive about their experience of the scene. Interview data was collated into themes of taste and distinction, community and place, and anti-corporate/'DIY' culture for analysis and interpretation. Participant observation was carried out in the three micropubs with the knowledge and consent of the owners. In the main, this was undertaken around live music sessions and included some weekday evenings as well as weekend afternoons and evenings. The researchers carried out the observational research individually and as unobtrusively as possible. Observational data was recorded

\footnotetext{
${ }^{3}$ All are anonymised in this paper.
} 
in notebooks and then collated for joint analysis according to the same themes as the interview data. In total, we carried out 15 sessions of participant observation between March and August 2017. From the outset, we observed that the Canal Quarter scene was in the midst of a key moment of evolution and change. We were mindful of this both in our questions to research participants and in planning the observational research, which included attending events to celebrate micropub anniversaries and observing reactions to the impending sale of one of the venues.

\section{Music and Ale: Creating New Leisure Spaces}

Before the Beer Engine opened as Skipton's first micropub in spring 2014, the town's only specialist real ale bar was the Narrow Boat, similarly situated amongst the quaint cobbled side streets of Canal Quarter. The Narrow Boat is part of a regionally-based chain of managed free-houses offering a regularly changing selection of real ales which also lets out an upstairs function room to Skipton Folk Club each Monday night. At the time, the only other Skipton pub providing regular live music was the nearby Cock and Bottle, a tied-house at which the recently arrived tenant had introduced an open mic night on Thursdays and a band night on Fridays. Whereas the folk club was the exclusive domain of 'hard-core' folk enthusiasts, the music nights at the Cock and Bottle were a way of increasing bar sales in a competitive market place. In neither pub did drinkers have much influence over what musical events were booked or what beer was sold. Nevertheless, it should be acknowledged that Skipton Folk Club remains one of the 'singers clubs' which help to keep a radical (albeit middle-class appropriated) folk music tradition alive in the region. So too, the open mic at the Cock and Bottle (organised by one of our interviewees) has helped some aspiring musicians to get bookings at the new micropubs.

On opening, the Beer Engine immediately attracted real ale drinkers with a constantly changing selection of beers from local and not so local independent breweries, with the owners initially sticking to a basic micropub model, promoting conversation and shunning both live and electronic entertainment. The micropub ethos, and its application at the Beer Engine, is explained by co-founder 'Simon':

[Micropubs are] like one room ale-houses with no other distractions. Quite a few of them ban mobile phones, so the focus is on chatting...

...on a cold Wednesday night... when you get a few in [the Beer Engine] you get a great atmosphere because they are all close together and they are all forced to talk.

As with the other micropubs we discuss, the Beer Engine does not serve draft lager. Unchanged in lay out and decor since opening, the small single room space connotes a comfortable but 'no-frills' ale-house ambience. By contrast, the Sound Bar, which opened 12 months later in spring 2015, combines a second-hand vinyl record exchange and bar. A micropub insofar as patrons can gather round the small bar and drink real ale, the Sound Bar also features a constantly playing record turntable, rock ' $n$ ' roll memorabilia, and record stands in between its mis-matching tables and chairs. Whilst the Beer Engine was Skipton's first 'micropub', it nevertheless conforms to preconceived expectations of an imagined Dales market town. The Sound Bar, on the other hand, is 
fashioned on the more contemporary, cosmopolitan notion of combining different functions in the same place; and in doing so, inevitably signifies meanings not only about what it is but also about who it is. Rather than just beer not lager, the Sound Bar is also coffee and gin, proclaiming a more urban as well as a more gender-inclusive space. A glance round the memorabilia covered walls indicates not 'pop' music but an emporium of rock connoisseurship: Led Zeppelin, The Clash, Joy Division. Taste in drink is here articulated with taste in music, the bar and walls signposting whose space this is and whose it is not. Early-closing times also indicated the owners' initial intentions that this should be a place for browsing and chatting but not partying. As 'Mark', one of the cofounders explains:

We shut at 9 o'clock because we don't want people coming in who may not mean any harm but have had too much cheap lager somewhere and end up upsetting people.

Within weeks of opening, the Sound Bar began staging some ad-hoc live music and DJ sessions at weekends, including some solo acoustic performers and a local Northern Soul DJ. By spring 2016, a year after opening, the popularity of the live music sessions had led to them becoming regular Sunday afternoon events with solo, duo and larger groups of musicians sometimes travelling from some distance to play there. As with the Beer Engine, the Sound Bar was attracting a different mix of patrons to other local drinking places. In both cases, this included real ale drinkers, and in the case of the Sound Bar, a noticeable number of patrons who identified as alternative in dress and appearance. Whereas, to some extent, the Beer Engine attracted the Narrow Boat's (real ale) customer-base, many of the Sound Bar's patrons appeared as new faces on the local drinking scene and were initially unfamiliar with one-another. It did not, in other words, attract a pre-existing local 'crowd'. Co-founder 'Mark' sums-up the alternative Sound Bar 'vibe' as follows:

You'll get a man who looks like a multi-millionaire sat at the bar...along with a lad with tattoos and a beard and earrings. They don't know each other but they're happily talking about music and things, and laughing and joking.

Also in spring 2016, the owner of an established narrow boat hire business converted his canal-side café into the Boat House Bar, a further micropub in close proximity to the other two. Like the Beer Engine, the Boat House has a constantly changing selection of real ales, but unlike either of the other two serves cooked food. It also differs by having an outside area where drinkers can congregate and local passers-by can check who's about and what's going on.

At this moment, a new local music and beer scene became evident as, encouraged by the Sound Bar's popularity, both the Boat House and the Beer Engine started to host ad hoc live music sessions. Up to the time of our research these sessions have increased in regularity, with live music taking place at one or both venues at some time during most weeks. Typically, the Beer Engine books solo acts on Saturday evenings, whereas the Boat House has a varied bookings schedule and also hosts a monthly Sunday afternoon 'jam session' at which local acoustic instrumentalists gather in the bar to participate in amateur music-making. Some solo acts now perform on an occasional basis at all three venues, mirroring and encouraging a habit amongst real ale drinkers and music fans to socialise between these places. 


\section{The Emergence of a New Local 'Scene'}

What we refer to as the emergence of a new local music and beer scene was made possible through the enterprise of individual entrepreneurs - each identifying a similar small business opportunity within Skipton's Canal Quarter and competing with oneanother in their newly-created local market place. However, real ale drinking, musicmaking and music fandom can all form prime sites of communicative leisure, both through the feelings of belonging they can engender and through the local networks around which they frequently organise. Notably, the area has a particularly active local CAMRA branch (Keighley and Craven) which has put Skipton on the real ale map by organising the annual Skipton Beer Festival since 2007; the monthly 'jam session' at the Boat House previously took place at another local pub for several years; and in June 2016, as the new scene was becoming evident, one of our interviewees started a Facebook group which has become an informal platform and 'gig guide' for local live music-goers. Each of these - as groups and/or as members of groups - constitute active participants in the new local music and beer scene; their voices each carrying some (sometimes conflicting) potential sway over the character of the social spaces which are created, the performative practices which are established, and the tastes that are accepted and accommodated.

Where the Beer Engine provided a second gathering place for local real ale drinkers whose tastes were previously catered to by the Narrow Boat alone, with the opening of the Sound Bar the following spring, further characteristics about the mix of people who were gathering in these places became apparent. From the start there was significant overlap, and whilst the emphases of these two new social spaces were respectively on beer and on music, they shared common signifiers of alternative meaning. These two intimate single room spaces respectively denoted a market town and a more urban ambience, yet each created a sense of non-corporate informality in their fittings, décor, signage and range of offerings, as described in the previous section; and more particularly, perhaps, in the manner of interactions they fostered. In each case, the owners (a male/female couple and two male business partners) were middle-aged people from other walks of life in nearby industrial towns for whom Skipton provided an opportunity for ventures in which they could pursue their own enthusiasms for, respectively, real ale and vinyl records. Initially, by only opening five days a week (Wednesday to Sunday), the owners could be more-or-less ever-present; each employing only a minimal part-time staff of like-minded enthusiasts. In both cases, the owners would introduce themselves to new customers, readily explaining where they were from, what they were aiming to do, and discussing further ideas with those customers who showed a particular interest. As customers of each of these new ventures, the authors became aware of being part of an emerging local leisure scene.

Whereas many Beer Engine customers were already part of a local real ale community, the Sound Bar attracted a different mix of customers to any of the other bars and pubs in Skipton. This is partly explainable by the different purpose that it served, for whereas the majority of evening customers were there primarily for social drinking many of the daytime customers were primarily there to buy, sell and talk about vinyl records. Like real ale bars, second hand record shops have long been perceived as male domains, 
attracting a clientele approximating to Nick Hornby's (High Fidelity) description of 'young men, always young men, with John Lennon specs and leather jackets and armfuls of square carrier bags' (1995: 30). Similarly, the Sound Bar's early customers included local groupings of the ever-more multi-generational tribes of male rock connoisseurs, some from neighbouring towns such as Keighley and Colne, whose weekend visits quickly established it as a meeting place and record exchange. At the same time, a range of beverages and gins, relaxing surroundings, and welcoming, reassuring owners appealed to the tastes of an expanding and previously un-catered for section of the local population who craved something other than chain-operated and tourist-oriented pubs and cafes. This section included at least equal numbers of women to men as well as ones who had recently moved to Skipton, and a further attraction of the Sound Bar for these people (alike with the Beer Engine and the Narrow Boat for some of them) was the absence of either loutish behaviour or locals cliques. As female Sound Bar regulars explain:

You can come in, have a coffee, have a beer...you could be sat at the bar; nobody would be looking at you or want to know what you're doing. ('Sandra')

...when I come in here I know they're not going to be slobbering about all over the place. There's not going to be any trouble or fighting. ('Jane')

And as a vinyl record exchange, the Sound Bar attracts a wide age range of people and does not conform to Hornby's description or to more academic notions of rock record collecting as a male-dominated domain (Bannister 2006; Straw 1997). The co-founders explain thus:

I always looked upon record stores as...not really attractive to females and piled high to the rafters with dusty records. Women can't be bothered with that kind of stuff, whereas they like coming in here because hopefully it's fairly clean and organised. ('Pete')

We're getting twenty-year-old girls in who are buying vinyl from the '80s when they weren't even born... ('Mark')

The age and gender diversity of vinyl collectors which the Sound Bar attracts is evidenced by some of those we spoke to, from the middle-aged 'Jane' who "grew up with vinyl [spending] hours at weekends in record shops", to the younger 'Rick' whose "mum and dad always had a turntable" and for whom "it's a bit like a trip down memory lane". But here, collecting and discussing vinyl records is more than simply a nostalgia-driven pastime. It is one of the set of signifiers which distinguish Sound Bar regulars from the commodified leisure practices of the undiscriminating crowd: a crowd from which both the customers and owners of each of the three micropubs in Canal Quarter actively sought to distance themselves from the outset.

The question of whether or to what extent this form of distinction is linked to class position is a complex one. The most significant role which the Sound Bar played in defining a new, alternative local leisure scene was in bringing together a taste for consuming non-mainstream music and a taste for consuming real ale in one place. Whilst each of these leisure activities requires a certain level of cultural capital in order to participate fully, whether preferences for these activities can be explained in terms of 
Bourdieu's notion of 'habitus' is less straightforward. As with rock fandom, real ale drinking has traditionally been regarded more in terms of a gender- rather than classspecific activity; these activities more recently, perhaps, forming symbolic refuges for masculinities under threat across class divides. However, this perception is similarly under challenge both within Skipton's Canal Quarter scene and more generally. As Beer Engine co-founder 'Simon' opined, "it's really a 'blokey club' I think, but there's certainly a lot more females and lager drinkers now drinking real ale". 'Simon's' view of an increasing number of female real ale drinkers is supported by our own participant observation but his comment on lager drinkers turning to real ale is also telling.

Along with the no draft lager policy maintained by the three micropubs and efforts to 'convert' some lager drinkers to real ale, disdain for lager culture was expressed by several interviewees. This disdain is commonly described in terms of the 'lager lout' phenomenon, the 'folk devil' at the centre of a moral panic appearing during the late1980s and associated with young working-class 'binge drinkers' (see Marsh \& Fox 1992: 10). A culture which congregates in pubs featuring Sky Sports and ritualistically participates in 'stag' and 'hen' trips, rowdy groups perceived by some as 'lager outs' are evident in Skipton at weekends as they are around many towns in the region. 'Lager louts' can also impinge on real ale drinkers territory; a notable example of this being the Trans-Pennine Ale Trail, a train-based pub crawl between Stalybridge and Dewsbury which was initiated by real ale drinkers but has more recently been hijacked by stag groups from Manchester drinking lager and 'shots' and causing a nuisance to local residents. Middle-class 'Dan's' description of Skipton's new micropubs as "quality drinking establishments" which attract "inoffensive beer drinkers" might infer that the construction of a real ale-lager dichotomy is based at least in part on class-defined distinctions of taste and behaviour. So too, perhaps, there is a suggestion that 'authenticity' remains the exclusive realm of a 'knowing' elite. But 'Dan' is also selfdeprecating, recognising that "the choice [of real ales] has become so vast...it's almost in danger of becoming as snobby as the wine industry". Indeed, local real ale drinkers who identity as working-class were more forthright about their distinction from 'lager louts'. As 'Rick' opines: "I'm not saying that everybody that drinks draft lager is an idiot but the majority of them are"; whilst 'Martin' advises that "stag dos... are not welcome in these places... Those drinkers stick to the main drag". This last statement accords with the observations of 'Mark', one of the micropub owners: “...there's a little vibe to [the Canal Quarter] which attracts a certain kind of people... The High Street's got a different vibe to it, a totally different clientele".

Amongst other things, these observations on real ale and lager cultures raise interesting questions about the significance of place for cultural identity in terms of region, rural urban dichotomies, the reclamation of authentic place and the idea of local. In Yorkshire and Lancashire real ale holds a special place in male working-class culture (Spracklen et al 2013B: 305), nowhere more so than in the Pennine towns to the south of Skipton in which brewing traditions go back to the early industrial age. In this respect, real ale culture in the town not only provides a sense of belonging where the structures of male working-class community have elsewhere been eroded, but real ale can also here be consumed as an authentic symbol of place (Sims 2009) for recent converts, newcomers and tourists alike. It is notable also that in contrast to the hipster bars of more urban locales, the Skipton micropubs do not sell craft beer and the regular clientele conform to a more diverse set of cultural identities and cover a broader age range. As Sound Bar 
co-owner 'Pete' explains, “...some people, when they walk in, we think they might not seem to fit, but it's a state of mind thing; it's not what you're dressed like or how old you are". The scene is, to an extent, peculiar in so far as demanding only that participants exercise authentic taste in beer and in music and conform to a code of conduct which excludes rowdy groups on 'stag dos' and requires being 'inoffensive' towards others: a code that is from time-to-time frivolously displayed in the Beer Engine in the form of the 'Dewsbury Rules'4, in order to dissipate signs of tension amongst drinkers.

With the conversion of the Boat House to a real ale bar in 2016, the emerging scene took a further local twist with this bar being operated by a long-time Skipton family who already ran a well-established narrow boat hire business from Canal Quarter. This addition provided the scene with an authenticity of place that neither of the pre-existing micropub businesses could fully achieve. To some degree confirming the acceptance of micropub culture amongst local residents, the Boat House also drew new custom from the local canal boat community, a group who both added extra colour to the social mix of the scene and who themselves follow an alternative and 'DIY' lifestyle ethos. Located in a picturesque canal side location, the Boat House differs from the other micropubs by having an outdoor area for drinkers to congregate. In contrast to the enclosed, slightly subcultural feel of the Beer Engine and the Sound Bar, the Boat House and its clientele are visible to passers-by and those who want to check who's out-and-about. In this sense it opened up the emerging scene to wider view, evidencing the more alternative mix of people who were inhabiting the Canal Quarter scene from those on the High Street; encouraging and discouraging accordingly.

Whereas the social dynamics of many larger towns and cities have long given rise to the establishment of 'boho' quarters, often low rent districts fostering alternative street scenes in the vanguard of gentrification projects, the cultural labelling of areas within small market towns is less common. For Skipton, to the extent that the Canal Quarter may be described in terms of an alternative street scene, it is a new development. Notably, it also coincides with an invasion of branded leisure outlets around the High Street over the last five years, including Costa Coffee, Café Nero, Pizza Express, Starbucks and Wildwood, in addition to the pre-existing selection of wholly chain operated, managed house pubs. In the Canal Quarter, by contrast, the cafes and eateries are all independently operated, whilst, with the exception of the Narrow Boat, the chain owned pubs are all tenanted houses, enabling a degree of local autonomy. With the emergence of the micropub scene coinciding with an increase in branded outlets on the High Street, these factors have affected change not only in terms of where local people conduct their leisure time but also in their socio-spatial perception of the town, as apparent in 'Martin's' comment on drinkers who "stick to the main drag" and 'Mark's' reference to the High Street's "different vibe". For some at least, this new sense of place is consciously linked to an anti-corporate perspective as apparent in Sound Bar regular 'Sandra's' comment: "I would...rather go into an independent coffee shop in Skipton...than the Starbucks and I know a lot of people feel like that". A further development to encourage the emergence of a micropub scene with an anti-corporate, local ethos has been the establishment of several new small/micro-breweries in the area.

\footnotetext{
${ }^{4}$ The 'Dewsbury Rules' refers to a self-opinionated former patron and is a list of some 20 topics which are deemed likely to cause argument or offence if raised in open conversation at the bar. Every third or fourth entry on the list is 'Margaret Thatcher'.
} 
Not only has this enabled the micropubs to buy local beer direct from local breweries as and when required, but it has also led to the growth of social interaction in the form of brewery 'open evenings' and 'meet the brewer' events at the Beer Engine; examples of some of the communicative leisure we discuss in the following section.

\section{Communicative Action that Binds and Defines}

Whilst brewery events have been a feature of communicative activities amongst Beer Engine regulars from the outset, the scene that has emerged around all three micropubs since spring 2016 has been commonly defined around musical events. Across Britain, a proportion of pubs have long featured live music; some city pubs and occasionally pubs in smaller towns becoming primarily known as music venues. What is far less common, except where live music is specifically marketed as musical tourism, is to come across a cluster of music pubs in a small market town. In part, it is the very proximity of Canal Quarter's three micropubs together with the flow of regular customers and musicians between them that defines these new local leisure spaces as constituting a local 'scene'. In terms of scale and level of musical creativity it is, of course, a far cry from the live music scenes described by such pioneers of the scenes perspective as Sara Cohen (1991) and Barry Shank (1994) in relation to Liverpool and Austin respectively. Nevertheless, 'scene' is a relevant term as used for the purpose referred to by Andy Bennett (2004: 223) of "map[ping] the socio-cultural significance of music in the context of everyday life". So too, as sites of 'semiotic disruption' which "produce momentary transformations within dominant cultural meanings" (Shank 1994: 122), scenes connote the possibilities for communicative action in the struggle against the forces of instrumental reason.

However, Skipton's Canal Quarter scene displays neither the spectacular nor radical characteristics apparent in some club-based scenes such as nearby Bradford's Underground and 1 in 12 clubs, but is rather characterised by the sort of locally defined meaning observed by Ruth Finnegan (1989) in her grounded study of amateur musicmaking in Milton Keynes during the 1980s. The musical practices Finnegan describes amongst local neighbourhood pubs in Milton Keynes can be read as evidencing the performance of communicative action: live music being "arranged to fit the varying interests and networks in the locality rather than on a mass entertainment basis" (ibid: 235), with particular performers being booked according to the expectations and requests of pub regulars (ibid: 232). For some older participants in the Canal Quarter scene the sort of performativity documented by Finnegan in the 1980s forms a nostalgic yearning; the founders of the Sound Bar describing how the "old local has disappeared", that "ale and music, to me, have always gone hand-in-hand" ('Pete') and how in Skipton they'd "tapped into" a "kind of working-class nostalgia" ('Mark'). Here, the demise of the 'local' is blamed on big pub chains:

Some of these more established pub chains don't have their own identity anymore because some guy in London says 'This is how it should work'. ('Mark')

They turned pubs into a property empire and they screw the landlords over to such an extent that the turnover of landlords is every couple of years. ('Pete') 
Similarities with Finnegan's observations are evident in the forms of communicative action at work amongst Canal Quarter regulars in their descriptions of local networks and performative practices:

There's a network between the [local] breweries and the micropubs, there's a network among the public, and there's a network with the musicians. ('Jane')

It's not just a micropub, it's not just real ale, it's not just the music, it's not just the locals it's what they produce when they're all fused together. ('Dan')

As well as being a Canal Quarter regular, 'Dan' fronts a local rock band and performs as a solo act around the micropubs. He describes his experience of playing the local live music scene thus:

It's vibrant, it's now, it's immediate, it's off-the-cuff, and you get the mistakes and you get the 'craic'.

These descriptions highlight the value placed on local performative practices and on informal networks in the construction and production of meaning amongst scene participants. It is a scene that largely excludes and is excluded from the structures of 'official' culture. Micropub music events are not generally advertised on local tourist information platforms and whilst the district council has sought to promote a newly renovated town hall as a music venue, local musician 'Greg' explains that the musicians themselves have not been consulted about this. Rather, a network of local musicians has emerged through 'Greg's' own open mic nights at the Cock \& Bottle and through playing the micropub circuit.

For Canal Quarter regulars, the Facebook group started by 'Sandra' in June 2016 provides one of the main networks through which musicians and micro-publicans keep locals informed about upcoming events and locals arrange meet-ups and exchange news about what's happening around the local music scene. 'Sandra' explains that having initially formed the Facebook group to meet up with other socially isolated rock fans at major gigs, it has since taken on a more local purpose:

When I started, it wasn't to advertise local music, but that's mostly what it's used for now.

I think it's actually changing people's lives. There are some people, who might live on their own or, y'know, never go out, and I say, "Well just come along". ...they know they can come along and who'll be here [at the Sound Bar].

The most visible presence of this group is at the Sunday afternoon Sound Bar sessions, where early-comers claim a large table in the middle of the bar at which group members who arrive on their own know they will be made welcome. By early 2017 the popularity of the Sunday sessions was regularly packing the bar to capacity, with drinkers spilling out onto the street, encouraging nearby pubs and micropubs to stage live music simultaneously or straight after the Sound Bar sessions:

I arrive at the Sound Bar at 3pm, where a four piece 'Hellbilly Skiffle' band from Keighley are already into their first set - crammed into the small performance space to the side of the entrance. Owner 'Mark' is standing by the door: 'Good luck with getting in there' he 
greets me with a smile. Sunday regulars have arrived early to get their favourite tables and the walkway is packed with people shuffling to and from the bar at the rear of the room, beside which more people are sat on the staircase up to the toilets from where they can view the band. Whilst piling through a set including Muddy Waters, Hank Williams and Chuck Berry numbers, the lead singer climbs onto a coffee table in order to be visible to those stood around the bar. By the second set, the crowd of mainly regulars has been augmented by groups of local male drinkers 'doing-the-rounds' and attracted in by the raucous sounds emitting from the entrance. Some of those stood in the walkway move out onto the pavement to avoid the increasing congestion and jostling as people try to find their way to the bar. Overall, the crowd are rather more male than female, ranging in age from early-thirties to late-sixties and occupational groups from professionals to labourers. Voicing a nostalgic yearning, one retired professional in his sixties remarks that 'This feels like being back in the Students Union', whilst a local part-time musician of similar age likens the experience to 'a Nashville honky-tonk'.

With the extended second set still in full swing, I leave the Sound Bar at $5 \mathrm{pm}$ and walk across to the Boat House where local singer/guitarist 'Dan' is commencing a solo acoustic set. Initially, 'Dan' performs to some fifteen regulars, but others soon follow across from the Sound Bar. Along with rock covers, 'Dan' performs some self-penned numbers including his homage to the local music scene which contains the lines Shut the front door with my guitar on my back, I'm on the local circuit now / Passed silent barges with their smokin' chimney stacks, I wouldn't change this anyhow (anonymous participant, 2017). His audience includes two regular couples who moor narrow boats in the canal basin as well as younger, alternatively identifying males with facial studs wearing Alter Bridge (heavy metal band) and Levellers (folk-punk band) T-shirts. Amongst those who follow me to the Boat House is a Northern Soul DJ of local repute who mentions to me that he is hoping to organise a bank holiday DJ gig at the Sound Bar. (Field notes, $19^{\text {th }}$ March 2017)

The above field notes refer to the first of six Sunday afternoon participant observation sessions undertaken in spring 2017, during which the presence of regular scene participants became increasingly evident. The authors were able to experience at first hand a growing and excited sense of belonging amongst scene regulars, with social interaction blossoming between ones who'd only recently been strangers to one-another. Spotting someone they recognised from a previous Sunday, participants started to approach one-another, exchanging notes about musicians and information about other events that were taking place. It was mainly through being included in these social interactions that the authors recruited research interviewees. So too, some of the young musicians from 'Greg's' open mic nights started to attract small followings, including 17 year-old singer-songwriter 'Craig' who we observed performing at both the Boat House and the Beer Engine within the space of a week. At 'Craig's' mid-week Boat House gig part of the micropub's first anniversary celebrations - the audience were exclusively locals who mostly knew one-another; the inclusivity of the scene being evident in the conviviality that developed as customers supped a specially-brewed anniversary ale and jokingly shouted out requests for "AC/DC" and "Elton John" in between 'Craig's' folk and blues numbers. The Beer Engine remains the primary meeting place for real ale aficionados, and at 'Craig's' Saturday night gig something of a split was evident between an older group of regular couples who gather to talk and drink ale and a younger group of mostly males who go for the music. Nevertheless, all were familiar with one-another and co-existed amicably throughout the evening, everyone adhering to a code of 
behaviour which requires real ale drinkers to be able to take their drink without becoming unsociable or belligerent.

The Beer Engine is also the one Canal Quarter micropub to organise trips out for regulars, sometimes in conjunction with its sister micropub - Gallagher's Ale House in nearby Cross Hills. In June 2017, a male regular described a recent minibus trip to the Grassington Festival to support 'Naomi', a young local singer who was performing on the village square stage: "The Gallagher's lads were a great laugh and the trip back was mental! Naomi and her guitarist were on the back seat getting the singing going." As with 'Greg', 'Dan' and 'Craig', this is another example of how a group of aspiring and part-time musicians form part of the scene rather than just providing paid entertainment. Similarly, off-duty bar staff can frequently be found socialising in their own workplaces and the other micropubs; one of the Sound Bar staff explaining that "People ask why I come in on my day off, but it's my favourite bar!" Just as the introduction of live music at the Sound Bar signalled the emergence of this scene, so too it was primarily the Sound Bar that encouraged opportunities for more communicative leisure. As joint owner 'Mark' reminded one of the authors, it was the author's suggestion to start the monthly music quiz that has since become a Sound Bar fixture. Similarly, in June 2017 the owners arranged for a young female quiz regular to host a special music quiz to mark her departure from Skipton. 'Christine' had worked at a neighbouring independent bakery whose owner drops off left-over pastries each evening for Sound Bar staff and customers. A single woman, who usually went in the Sound Bar on her own, 'Christine' had gained a circle of friends there over the previous year or so, both male and female an example of the bar's gender inclusivity and the owners efforts to make it an attractive place for single women. Her farewell event, held on a Thursday night like the regular music quiz, attracted many of the regular quizzers, at the same time adding to the meaning of the bar as a place of communicative leisure in which regulars are active participants. Similarly, the monthly acoustic 'jam session' at the Boat House is an open event for local amateur music-making at which anyone can turn up with their instrument and join in. Although this event pre-dates the Canal Quarter scene, its new venue further encourages the performance of communicative leisure due to increased visibility.

Whilst music quizzes and amateur music-making provide opportunities for scene participants to display their cultural capital, these performative practices and aesthetic choices are not necessarily constrained within Bourdieu's notion of 'habitus', in which cultural preferences are read as being largely predetermined by class position. Rather, they can more usefully be read as constitutive of an emergent 'taste culture' (Gans 1974), enjoyed by a 'taste public' made up of individuals who share similar aesthetic standards across class boundaries. The Canal Quarter scene forms part of a taste culture in which symbolic boundaries - both aesthetic and ethical - are created around notions of the 'authentic' and the 'local'. 'Authenticity' covers a number of meanings (see Peterson 1997: 206-9), but here primarily connotes the 'real' in opposition to the 'artificial' - as in 'real ale' (not filtered or pasteurised) and 'live music' (not pre-recorded or digitally reproduced). Likewise, the 'real' is articulated in a Gramscian sense with that which is local and independent in opposition to the global and the corporate, thus delineating a set of ethical preferences which embrace the organic, the acoustic and the artisanal. These ideas are further articulated aesthetically with such relics of the industrial age as narrow boats and vinyl records. Regardless of their original roles in the service of industrial capital, such cultural artefacts have become symbolic of alternative 
lifestyles and systems of exchange which eschew the grip of corporate consumerism. They represent the leisure activities of Rojek's (2005) 'active citizen', organised locally and motivated to transcend commodification (see Spracklen 2009, p. 26). Moreover, it is part of a taste culture that is neither bound by Rojek's distinction between 'good and bad leisure' (being a drinking culture which confounds middle-class norms of healthy living), nor Bramham's (2006) argument that freely chosen leisure is denied to the workingclass. Rather, as part of a wider micropub and real ale community, the Canal Quarter scene celebrates 'traditional' working-class leisure practices in deliberately non-class specific leisure spaces.

\section{Communicative Leisure and the Intrusion of Instrumental Reason}

Nevertheless, Canal Quarter's micropubs form contested social spaces, and the performative practices described in the previous section are susceptible to the forces of instrumental leisure. A month before the trip to support 'Naomi' at Grassington Festival, the young singer performed at the Beer Engine on a Sunday afternoon as part of the micropub's third anniversary weekend. On that occasion, 'Naomi', who had recently reached the finals of a national songwriting competition, brought along a number of family and friends who were not Beer Engine regulars:

As 'Naomi' begins her second set her family and supporters gather in front of the performance space, listening attentively as she belts out her contemporary pop repertoire, accompanied by digital backing tracks. Between numbers a visiting female Sound Bar regular exclaims to me 'What a talent - here in Skipton!'

Meanwhile, many (mostly male) Beer Engine regulars mingle outside in the lane, chatting convivially over pints of ale. Towards the end of the set I join some of these regulars who appear largely oblivious to the music coming from inside the doorway. These are mainly rock fans who seem to put up with the Beer Engine staging a pop act that is not to their taste (perhaps as long as it doesn't happen too often and perhaps being more tolerant towards a young female performer). Mention of the music produces amused expressions and dismissive remarks such as 'Yeah, whatever!' Nevertheless, I detect a subtle sense that their space has been infiltrated by a different group. (Field notes, $7^{\text {th }}$ May 2017)

More noticeable was a change of ambience at the Sound Bar as the Sunday afternoon sessions became increasingly popular and attracted a less discerning crowd who drank bottled lager in the absence of draft, and who also started to use the bar as part of their Friday and Saturday night circuit. This produced a substantial increase in turnover, but by early August 2017 the bar was up for sale. "We've become victims of our own success" explained co-owner 'Mark', "We have to either expand or pack in". By Thursday $10^{\text {th }}$ August word had got round that the sale of the Sound Bar had been agreed, and the change of 'vibe' was increasingly apparent:

I arrive at the Sound Bar at 6.45pm. Unusually, there is only one customer who I recognise: 'Derek', one of our interviewees. 'I'm, glad to see you' he utters, 'I was beginning to feel out of place in here tonight'. There are a few people sat at tables and a group of six men and two women in their twenties and thirties stood at the bar, none of whom I recognise. Four of the men have shaved heads. They appear to be out on a drinking session and are quite noisy. They variously drink real ale, bottled Budvar lager 
and the bar's (strong) house cider. One of the women appears quite drunk. She wanders over to 'Derek', who ignores her. She then approaches me and says that I 'look like Rolf Harris'. I also ignore her and she wanders away. At close quarters she appears stoned as well as drunk. 'Derek' and I agree that there is a different vibe to usual for a Thursday evening. He's only still here because he's waiting for a friend.

Co-owner 'Pete' is working the record deck and looks pre-occupied. He's turned the volume up higher than normal, perhaps to drown out any swearing. Rather than playing his usual eclectic mix of blues, punk, metal and indie rock, he's keeping to more popular and conservative pop and rock. After a few more minutes some of the group at the bar start getting restless to move on and eventually do so. They leave as 'American Pie' is playing, some of them singing along at the top of their voices as they swagger out. At $8 \mathrm{pm}$ I walk round to the Boat House where a regular blues singer is due to start a session. The evening is still warm and a dozen or so real ale drinkers including several Sound Bar regulars are gathered outside. One of them mentions that he'd been in the Sound Bar earlier in the evening but didn't like the atmosphere. The bar's impending sale is one of the topics of conversation and is generally regarded as unwelcome news. (Field notes, $10^{\text {th }}$ August 2017)

\section{Conclusion}

Drinking real-ale and listening to live music are communicative leisure activities, freely chosen by our respondents as ways of finding community and identity. These communicative leisure spaces might be defended by the individuals in them as spaces that resist the wider homogeneity and commodification of culture and leisure at this moment in time. That is, real ale might be consumed because it is perceived as being more authentic, more local, and more traditional - or more working-class (Spracklen, Kenyon \& Laurencic, 2013). And micropubs might be thought as being spaces that resist the invisible hand of globalization on the decline of the high street and the rise of pubowning corporations. Listening to live music again might be said to be an act of agency, a performance of identity, which gives the audience good taste and a shared solidarity against the modern music industry's model of streaming stars plucked from reality television and YouTube. Such communicative leisure activities and spaces are used in the Canal Quarter to give people in it a sense of belonging and an ideological sense of solidarity and resistance. However, as we have shown, such activities and spaces are always at risk of being co-opted and colonized by instrumental rationality. Whether the Canal Quarter can retain this community and identity is dependent on the communicative rationality and action that survives.

\section{Bibliography}

Bannister, M. (2006) “'Loaded”: Indie Guitar Rock, Canonism, White Masculinities', Popular Music 25 (1): 77-95.

Bennett, A. (2004) 'Consolidating the Music Scenes Perspectives', Poetics (32): 223-34. 
Bourdieu, P. (1984) Distinction: A Social Critique of the Judgement of Taste. Cambridge, MA: Harvard University Press.

Bramham, P. (2006) 'Hard and Disappearing Work: Making Sense of the Leisure Project', Leisure Studies, 25 (4): 379-90.

CAMRA (2017) 'What is CAMRA?', Campaign for Real Ale [Internet]: http://www.camra.org.uk/what-is-camra.

Castells, M. (1997) The Power of Identity. Oxford: Blackwell.

Cohen, S. (1991) Rock Culture in Liverpool: Popular Music in the Making. Oxford: Clarendon Press.

Finnegan, R. (1989) The Hidden Musicians: Music-Making in an English Town. Cambridge: Cambridge University Press.

Florida, R. (2002) The Rise of the Creative Class. New York: Basic Books.

Florida, R. (2005) Cities and the Creative Class. New York: Routledge.

Gans, H. (1974) Popular Culture and High Culture: An Analysis and Evaluation of Taste. New York: Basic Books.

Habermas, J. (1984) The Theory of Communicative Action: Reason and the Rationalization of Society, vol. 1. Cambridge: Polity.

Habermas, J. (1987) The Theory of Communicative Action: The Critique of Functionalist Reason, vol. 2. Cambridge: Polity.

Hawkes, W. (2011) 'A Local Pub for Local People: "Micropubs" are Catching On', The Independent [Internet], 11 February: http://www.independent.co.uk/life-style/food-anddrink/features/a-local-pub-for-local-people-micropubs-are-catching-on-2217205.html.

Heying, C. (2010) Brew to Bikes: Portland's Artisan Economy. Portland, OR: Ooligan.

Hobsbawm, E. and Ranger, T. (1983) The Invention of Tradition. Cambridge: Cambridge University Press.

Hornby, N. (1995) High Fidelity. London: Penguin.

Jackson, J. (1994) A Sense of Place, a Sense of Time. New Haven: Yale University Press.

Lloyd, R. (2010) Neo-Bohemia: Art and Commerce in the Postindustrial City. New York: Routledge.

Long, J. (2010) Weird City: Sense of Place and Creative Resistance in Austin, Texas. Austin, TX: University of Texas Press. 
Marsh, P. and Fox, K. (1992) Drinking and Public Disorder: A Report of Research Conducted for the Portman Group by MCM Research. London: The Portman Group.

Peterson, R. (1997) Creating Country Music: Fabricating Authenticity. Chicago: University of Chicago Press.

Rojek, C. (2005) 'An Outline to the Action Approach to Leisure Studies', Leisure Studies, 24 (1): $13-25$.

Shank, B. (1994) Dissonant Identities: The Rock ' $n$ ' Roll Scene in Austin, Texas. Hanover, NH: Wesleyan University Press.

Sims, R. (2009) 'Food, Place and Authenticity: Local Food and the Sustainable Tourism Experience', Journal of Sustainable Tourism 17 (3): 321-6.

Spracklen, K. (2009) The Meaning and Purpose of Leisure: Habermas and Leisure at the End of Modernity. Basingstoke: Palgrave MacMillan.

Spracklen, K. (2016) 'Theorising Northernness and Northern Culture: The North of England, Northern Englishness, and Sympathetic Magic', Journal for Cultural Research, 20 (1): 4-16.

Spracklen, K. (2017) 'Bravehearts and Bonny Mountainsides: Nation and History in Scottish Folk/Black Metal', Rock Music Studies, 4(2): 102-16.

Spracklen, K. and Henderson, S. (2013A) "Oh! What a tangled web we weave": Englishness, Communicative Leisure, Identity Work and the Cultural Web of the English Folk Morris Dance Scene', Leisure/Loisir, 37 (3): 233-49.

Spracklen, K., Laurencic, J. and Kenyon, A. (2013B) "Mine's a Pint": Performativity, Gender, Class and Representations of Authenticity in Real-Ale Tourism', Tourist Studies, 13 (3): 304-21.

Spracklen, K. and Spracklen, B. (2014) 'The Strange and Spooky Battle over Bats and Black Dresses: The Commodification of Whitby Goth Weekend and the Loss of a Subculture', Tourist Studies, 14 (1): 86-102.

Spracklen, K., Timmins S. and Long, J. (2010) 'Ethnographies of the Imagined, the Imaginary, and the Critically Real: Blackness, Whiteness, the North of England and Rugby League', Leisure Studies, 29(4): 397-414.

Straw, W. (1997) 'Sexing Up Record Collections: Gender and Connoisseurship in Rock Music Culture', in S. Whiteley (ed.) Sexing the Groove: Popular Music and Gender. Abingdon: Routledge: 3-16.

Thurnell-Read, T. (2011) 'Off the Leash and Out of Control: Masculinities and Embodiment in Eastern European Stag Tourism', Sociology, 45 (6): 977-91. 
Tuan, Y-F. (1974) Topophilia: A Study of Environmental Perception, Attitudes, and Values. New York: Columbia University Press.

Williams, R. (1973) The Country and the City. New York: Oxford University Press.

Williams, R. (1977) Marxism and Literature. Oxford: Oxford University Press.

Zukin, S. (2010) Naked City: The Death and Life of Authentic Urban Places. New York: Oxford University Press.

Zukin, S. (2011) 'Reconstructing the Authenticity of Place', Theory and Society, 40 (2): $161-5$.

Zukin, S., Trujillo, V., Frase, P., Jackson, D., Recuber, T. and Walker, A. (2009) 'New Retail Capital and Neighbourhood Change: Boutiques and Gentrification in New York City', City and Community, 8 (1): 47-64. 